\title{
INDIVIDUOS Y UNIVERSALES EN ADOLFO GARCÍA DÍAZ
}

MAURICIO BEUCHOT

INSTITUTO DE INVESTIGACIONES FILOLÓgICAS

UnIVERSIDAD NACIONAL AuTÓNOMA DE MÉxICO

El doctor Adolfo García Díaz falleció en Maracaibo, el 5 de abril de 1995. Fue un profesor de filosofía, de origen mexicano, muy apreciado y respetado. Perteneció, en México, al Centro de Estudios Filosóficos, antecesor del actual Instituto de Investigaciones Filosóficas. Asimismo, colaboró en los primeros números de nuestra revista Diánoia. Por eso y por la estrecha amistad que nos unió, a pesar de la distancia, queremos ofrecerle como un sentido homenaje una reflexión sobre el tema de los individuos y los universales, que él abordó, y una discusión de sus tesis, por el beneficio que sus pensamientos y escritos causaron en nuestra meditación de este problema perenne. Pero, antes, quisiéramos ofrecer algunos datos del doctor Adolfo García Díaz.

Nació en Pachuca, Hidalgo, México, el 9 de septiembre de 1928. Obtuvo el título de maestro en filosofía por la Universidad Nacional Autónoma de México, en 1959. Fue miembro del Seminario de Traductores de griego y latín en la Facultad de Filosofía y Letras de la UNAM en 1951. Ese mismo año se desempeñó como profesor ayudante de Historia de las Ideas en Iberoamérica, en dicha facultad. En 1954 fue por breve tiempo profesor de la Facultad de Filosofía y Letras de la Universidad de Guanajuato. Pero ya en julio de ese año aparece como investigador del Centro de Estudios Filosóficos de la UNAM. También figura como miembro del Seminario de Problemas Científicos y Filosóficos, coordinado por el doctor Eli de Gortari. Secretario del anuario Diánoia, en 1957; por lo tanto, uno de los fundadores de esta revista, en cuyos cuatro primeros números vemos colaboraciones suyas. Fue asimismo profesor de la Facultad de Filosofía y Letras de la Universidad Veracruzana en 1957, y en la de la UNAM en 1958. En 1959 va a Venezuela, y figura entre los fundadores de la Facultad de Humanidades y Educación de la Universidad del Zulia, en Maracaibo. Fue director de la Escuela de Filosofía de dicha facultad, de 1963 a 1970. En 1978 asiste como ponente al Coloquio sobre metafísica y filosofía del lenguaje, organizado por el 
Instituto de Investigaciones Filosóficas en Oaxtepec, Morelos, México. (Fue donde tuvimos el placer de conocerlo.) También fue profesor invitado de la Facultad de Filosofía y Letras de la UNAM y en la Universidad Autónoma Metropolitana, Iztapalapa. Lo mismo se repite anualmente de 1979 a 1982. En 1984 se le nombra coordinador de la Maestría en Filosofía de su facultad en Maracaibo. Ocupa ese cargo hasta el 1o. de enero de 1985, año en que se jubila.

Entre otros escritos, García Díaz publicó "La noción del no ente en la filosofía de Parménides", Diánoia, no. 1, 1955; "La metafísica de Empédocles", Diánoia, no. 2, 1956; "Las bases de la cosmología de Anaxágoras", Diánoia, no. 3, 1957; "La analogía entre Dios y las creaturas según Santo Tomás", Diánoia, no. 4, 1958; "Nota sobre la similitud y los colores", Crítica, vol. XI, no. 33, 1979; "Sobre los universales", Revista de Filosofía, no. 12, 1989, y el libro Investigaciones Metafísicas, Universidad del Zulia, Maracaibo, $1992 .{ }^{1}$ Conoció tanto la filosofía griega como la escolástica, la filosofía moderna como la contemporánea. En Venezuela y en las visitas que hizo a México promovió el estudio de la filosofía medieval y colonial, consciente de que tenía muchas riquezas que podían dar fruto aun en la actualidad. La veía como un interlocutor valioso de la filosofía analítica, y la cultivaba sobre todo en lógica, filosofía del lenguaje y ontología.

Como un homenaje, pues, a su memoria, quisiéramos retomar la discusión del trabajo que elaboró sobre los universales, el cual presentó y nos tocó replicar en 1982 en el Instituto de Investigaciones Filosóficas, junto con José Antonio Robles, y que sigue siendo muy actual y sugerente.' Es una oportunidad para revisar ese tema y hacer nuevas reflexiones, ya a la distancia. $^{2}$

Lo primero que en su trabajo presenta García Díaz es la noción de individuo. Los individuos surgen porque son diferentes; por ejemplo, dos triángulos de distinto color, situación, etc. En cambio, los universales surgen a partir de lo común entre los individuos; por ejemplo, triangularidad, color, etc. Un individuo, en el sistema de García Díaz, es un todo, diferenciado de otros todos, pues se individualiza por ser diferente. Al ser un todo, tiene

1 La noticia de su muerte la hemos recibido por una carta del doctor Ángel Muñoz García, de Maracaibo. Los datos biográficos los hemos tomado de dos semblanzas que ha hecho el citado profesor Muñoz, una en el número de homenaje a García Díaz de la Revista de Filosofía, (Maracaibo), 1989, no. 12 y otra en el libro de García Díaz, Investigaciones Metafísicas, Universidad del Zulia, Maracaibo, 1992. Hemcs añadido algunos datos que le faltaban.

2 Cfr. A. García Díaz, "Sobre los universales", ponencia presentada en el Instituto de Investigaciones Filosóficas de la UNAM, México, en 1982, publicada después en el número citado de la Revista de Filosofía, pp. 15-31, y recogida en su obra Investigaciones Metafísicas, ed. cit., pp. 85-109. Citamos por esta última edición, poniendo entre paréntesis, en el texto, el número de página. 
partes. Sus partes surgen en el interior de él, por contraste mutuo, al modo como los todos surgen por contraste de unos con otros en el universo o mundo. Cada individuo, pues, se individualiza como diferente de otro de la misma categoría, y es composible con otro de diferente categoría. Esas partes son también individuales, es decir, son partes reales, no lógicas. Y no tienen partes que sean subclases, sino elementos. Por otro lado, un universal es, en el sistema de García Díaz, una parte que es capaz no sólo de entrar en un todo, sino en varios todos.

A primera vista, García Díaz parece responder más al problema de la individualidad que al de la universalidad. Esto sucede porque el tratar de los individuos es la base para poder teorizar sobre los universales. Plantea que todo es individual según grados o niveles, pero entonces igualmente podrá decirse que todo es universal según grados. Dice que donde hay individuos hay universales: propiedades y relaciones, pero trata poco acerca de su status ontológico, esto es, en qué categoría metafísica podrían colocarse (si en una especial de los "universales" o si se reducen a alguna otra). Se centra más en su aspecto epistemológico o gnoseológico.

Su principal contienda es rechazar como principio de individuación los individuos vacios, por contener petición de principio (cfr. pp. 88-89). Es decir, una parte del todo sería individual antes de la individualidad o individuación del todo. Lo que nos parece incorrecto - y es algo muy frecuentees que interpreta como individuo vacío la materia signata quantitate (es decir, la materia marcada con la cantidad) de la tradición aristotélico-tomista; lo cual no es exacto, pues ella no se da como individual antes del todo al que individualiza, sino simultáneamente; y, aunque no es individual antes de individualizar, tiene potencia para ello, pues su esencia es ser determinante o diferenciante. Tampoco es una parte que esté individualizada antes que el compuesto. Ella sujeta la potencia de universalidad de la forma y la hace individual, por la potencia individualizadora que ella tiene. Sólo si se rechaza el ser potencial se puede rechazar la materia como individuadora distinta del individuo vacío. García Díaz añade que los individuos vacíos serían aceptables si no fuera porque hacen admitir un mundo sobrecargado de entidades inferidas (desnudas en principio de propiedades). Igualmente nosotros nos oponemos a la noción de individuo vacío como principio individuador; pero, como hemos dicho, la materia aristotélica no puede entenderse como tal.

Por otra parte, rechaza como principio de individuación las relaciones asimétricas, como las espacio-temporales ("estar a la izquierda de", la posición o situs); pues estar a la izquierda de supone que los correlatos ya son diferentes; es decir, tales relaciones presuponen lo que se tiene sin ellas. Resultan superfluas (pp. 89-90). También nosotros rechazamos tales rela- 
ciones como principio del individuo. Ellas son más bien resultantes de la individuación.

García Díaz sostiene asimismo que las propiedades individuales son más bien universales, y que probará que son lo uno sin dejar de ser lo otro. Hay varios planos de individuación. Lo infiere de que, si dos triángulos no se distinguen en cuanto triángulos, esa propiedad podría ser un individuo por ser indistinguible; o que, si no se distinguen por el color, la propiedad de ser rojo, que parece indistinguible de sí misma, podría ser un individuo (p. 91). Esto se debe a su idea, ya mencionada, de que todo es individual o universal según grados. Esto se parece a la teoría aristotélica de los predicables, pero no excluye que haya cosas que ya no son individuales y otras que ya no pueden ser universales en ningún sentido.

Una tesis típica de García Díaz es que el nominalismo y el realismo encierran cada uno una parte de verdad, y su oposición es más bien aparente. Tienen una parte falsa y otra aprovechable. Asegura que el realismo no explica bien cómo un universal está distribuido en varios individuos; pues, o inventa ciertas expresiones misteriosas como "participación", "instanciación", etc., o principios de individuación que individualizan por ser ya individuales (materia signata quantitate, haecceitas, etc.; p. 92). Pero, como ya lo hemos apuntado, esos principios de individuación que ha mencionado no son individuales antes del compuesto, sino simultáneos a él. Si se los ve como individuales antes e independientemente del compuesto, se los está hipostasiando, reificando o cosificando. Es lo que parece hacer García Díaz.

El nominalismo y el realismo son incompletos; (a) por incurrir en regresión viciosa y (b) por no explicar bien la individuación. Pero, en cuanto a lo primero, David Armstrong demuestra que al menos el realismo aristotélico no incurre en regresión. Y, en cuanto a lo segundo, el mismo García Díaz da una explicación de la materia signata y de la haecceitas que no es correcta: no son individuos.

Añade que su tesis es que el realismo y el nominalismo pueden superarse y se puede tomar lo que de complementario tienen uno y otro, unificados en una concepción más amplia de lo individual. Allí coincidirían (p. 93). Según dice, la dificultad para el realismo es que exista el universal aun cuando desaparezcan los individuos. (Es la objeción de Meinong; pero el mismo García Díaz reconoce que no es una dificultad fuerte, pues no es propia de todo realismo. De hecho ya había sido considerada por los medievales. Los realistas moderados decían que, desaparecidos los individuos, no había universal in rebus, pero sí en la mente.) ${ }^{3}$ La dificultad del nominalismo es que no habría dos individuos que tuvieran las mismas propiedades; pues,

${ }^{3}$ Cfr. M. Beuchot, El problema de los universales, UNAM, México, 1981. 
aun cuando sean instancias, son individuos diferentes en esos individuos que las poseen (p. 94).

Según García Díaz, las dificultades de realistas y nominalistas tienen este origen: no haber reconocido que una propiedad o relación, tenidas por dos individuos al menos, son individuos en cuanto indistinguibles de sí y diferentes de otras: de aquellas de que difieren originariamente para ser, no de las que difieren una vez que ya son. Por ejemplo un color, para ser, difiere de otro color; pero sólo cuando ya es, difiere de un sonido (p. 95). Pero, ¿es esto así? Sólo dice que no refuta las otras posturas ni da pruebas de ello porque las demás en cuanto a la individuación tampoco lo hacen. Según él, su prueba residirá en dar un modelo que explique más fenómenos y de modo más económico. Nos parece que la diferencia, que García Díaz plantea aquí como principio de individuación, es más bien consecuencia o resultado de lo que funja como dicho principio. Y por eso tiene que ser otro. Por ejemplo, en el caso de Aristóteles y Santo Tomás, la materia signata quantitate es lo que causa que las cosas puedan ser individuales y, por lo mismo, diferentes.

Su planteamiento de base puede aceptarse: el problema no es tanto cómo se individualiza un universal, sino cómo se universaliza un individuo. Es un planteamiento aristotélico; el punto de partida es un individuo, para ver cómo es posible que pueda universalizarse. Se explica primero lo individual y, a partir de él, lo universal.

Para esa explicación, García Díaz rechaza los individuos vacíos, por ejemplo, los de G. Bergmann, y eso nos parece correcto. ${ }^{4}$ Su punto de partida es que las cosas individuales están compuestas únicamente de propiedades; y, ya que son compuestas, son individuos por ser diferentes en su composición (pp. 95-96). Pero aquí nos parece que hay una petición de principio: iser diferentes es una relación que individualiza o es posterior a la individualización? Él mismo ha dicho que una relación no puede individualizar, ya que una relación sólo se da entre dos cosas ya individuales. Así, si es una relación que individualiza, se supone lo que se debe demostrar. Pues, si la diferencia es lo que individualiza, pero la relación se da entre lo que ya es individual, ¿cómo puede la diferencia — que es una relación- individualizar? Dos términos de una relación no son individuos porque se dé esa relación, ya que si ella desapareciese, ellos no desaparecerían en cuanto individuos. Pero sólo lo dice de las relaciones asimétricas que se dan entre individuos, y ésta es simétrica. ¿No vale lo mismo decir que son diferentes porque ya son individuos, o son individuos porque son diferentes? ¿Y no incurre además en una regresión infinita relacional -de diferencias- como

4 Hemos discutido esa idea de los individuos vacíos en M. Beuchot, "Ontología y universales en Gustav Bergmann", Crítica, vol. XI, no. 33, 1979, pp. 19-48. 
la que atrapa a la relación de semejanza? Los individuos son individualizados por la propiedad relacional "diferencia". ¿Y qué la individualiza a ella, y así sucesivamente?

Cambiemos un poco las cosas. Digamos, haciendo un Gedankenexperiment o experimento mental, que lo que individualiza es, en lugar de la diferencia, la composición diferente. Así, es la composición diferente, y no la relación asimétrica de espacio, lo que individualiza (pp. 96-97). Pero la composición diferente es también una relación, sólo que una relación interna ("trascendental", dirían los escolásticos). Y muchos individuos pueden tener la misma composición interna y sin embargo estar individuados por relaciones de colocación. Luego la composición interna no es suficiente criterio de diferencia. Además, serían individuos igracias a las partes o al todo? Si a las partes, ¿tanto esenciales como accidentales? Si a las esenciales, eso no individualiza, sino más bien generaliza o universaliza. Si a las accidentales, sería una individuación muy accidental. Si a las esenciales individuadas, ¿sólo las individualiza la diferencia?, ¿o ya son individuales antes de la relación de diferencia?

Dado que García Díaz atribuye la individuación a la diferente composición de las partes en el todo, tiene que afrontar el problema de la constitución de las partes. Primero introduce el problema de cuáles son las partes últimas. Una parte última es la que por naturaleza sólo es parte, no puede ser un todo de ninguna manera (p. 98). De ahí pasa a las partes que pueden ser universales.

Una parte es universal si entra en varios todos. Pero una de las maneras de interpretar la composición es como adherencia, y ya ha dicho que la adherencia lleva regresión infinita. Si no se adhieren, ¿cómo se componen? La adherencia es una parte lógica. ¿No es lo composible también una parte lógica? Él mismo ha dicho que no acepta partes lógicas, pero sí acepta todos lógicos (pp. 98-99).

Ve que la relación de adherencia implica regressus. Por eso añade que se puede suplir por los grados de separabilidad de sus portadores (Husserl). Cuando al quitar una propiedad desaparece su portador, esa propiedad es esencial. El problema aquí es el relativismo de lo esencial y lo accidental. Pero el relativismo puede superarse si se dice que las propiedades que son esenciales lo son no relativamente a los observadores, sino al todo individual, i.e. como esencias individuales. Y esto se da in re (y de re; p. 100).

Con todo, acerca de esta distinción entre lo esencial y lo accidental, García Díaz habla mucho de partes esenciales y accidentales, así como de relaciones esenciales y accidentales (pp. 100-103). Acepta la distinción esencial/accidental; pero hace caso omiso de las numerosas objeciones antiesencialistas que pululan en la filosofía analítica, por ejemplo en el ala 
de Quine. También habla de relaciones internas, sin tomar en cuenta ni responder a las objeciones de Russell.

Uno de los problemas finales que García Díaz aborda en su trabajo es si la autoidentidad es anterior o por lo menos simultánea a la de diferencia. Lo resuelve diciendo que es posterior, y afirma además que la relación de autoidentidad es de razón, al revés de la relación de diferencia (p. 105). Ciertamente es una relación de razón, y más bien es una relación trascendental en sentido tomista. A nosotros nos parece que es simultánea a la diferencia, como buena propiedad trascendental que es, y asimismo nos parece que resulta de la labor del principio de individuación. La prueba que aducimos es que no hay entidad sin identidad (o autoidentidad), y que haya entidad resulta de la composición de los elementos de la misma, entre los cuales se encuentra el elemento individuador o principio de identidad.

Vemos, pues, y en conclusión, que para García Díaz el problema de los universales se presenta conjuntamente con el de lo individual. Es relativo a este último, y toma la forma de explicar cómo lo individual se hace universal. Para ello examina cómo las propiedades individuales se multiplican en los individuos, lo que explica que lo universal se distribuya entre ellos. Y para eso analiza cómo los individuos se individualizan. Adopta una postura que se había dado en algunos autores medievales tempranos, como Boecio y Teodorico de Chartres, para quienes lo que individualizaba era la diferencia, o la diferente composición de los elementos o partes del todo individual. ${ }^{5}$ Pero a nosotros nos parece que ello es posterior a la labor del principio de individuación, como la materia signata quantitate. García Díaz no lo acepta, por parecerle que es otra forma de la noción de individuo vacío, la cual encierra muchos problemas. A nosotros nos parece que es verdad que la noción de individuo vacio es problemática (sobre todo, tiene el problema de encerrar petición de principio, pues ya posee la individualidad que tiene que explicar); pero lo que no nos parece es que la materia aristotélica sea un individuo vacio, es algo muy distinto. Por lo tanto, no le afectan las objeciones que se le dirigen, ya que no supone la individualidad previa a la individuación del todo compuesto, sino que es simultánea a él. Creemos que la noción aristotélico-tomista de materia signata, como principio de individuación, sale incólume de estos ataques (debidos a una interpretación incorrecta), y que puede explicar la dinámica de la individuación, base para poder resolver el problema de lo universal.

El abordaje que hace García Díaz del problema de los universales a través de la individualidad es sumamente sugestivo. Aceptamos la mayor parte de

5 Cfr. J.J.E. Gracia, "Individuos como instancias", Revista Latinoamericana de Filosofía, vol. 8, no. 3, 1982, pp. 202-204; y "Thierry of Chartres and the Theory of Individuation", The New Scholasticism, vol. 58, no. 1, 1984, pp. 1-23. 
sus planteamientos y propuestas. Sobre todo su discusión de los individuos vacíos como principios de individuación; lo único que no aceptamos es la identificación que hace de la materia aristotélica con el individuo vacío. Tanto el problema de los universales como el problema del individuo son tópicos metafísicos fundamentales y arduos. García Díaz da una muestra de su perspicacia y profundidad filosófica en el tratamiento que hace de ellos. Un indicador del aprecio de García Díaz por la disciplina metafísica es el mismo título que puso a su libro: Investigaciones metafísicas. Tal vez esté inspirado en el de la célebre obra de Wittgenstein, pero tiene la orientación inversa hacia la ontología o metafísica. En esa obra recoge temas clásicos, como el de la metafísica de Empédocles (echamos de menos su trabajo sobre la metafísica de Parménides), y también recoge otros sobre las condiciones cognoscitivas de lo universal y lo particular, como en el caso de las relaciones de semejanza o similitud. Igualmente aborda allí el problema conexo de la identidad y la diferencia. Es el problema introductorio o preparativo para el de los individuos y los universales, ya que García Díaz presentará como principio de individuación la diferencia (de composición), que es la que hace que un individuo surja como un todo frente a otro. La identidad, que tiene diferentes tipos, como el que introduce Geach (distinto del de Leibniz), tiene que ver con los universales y la relación que con ellos mantienen sus respectivos individuos. Todo ello demuestra la altura metafísica del profesor Adolfo García Díaz, recordado en el afecto. 